TAYLOR, Charles. A secular age. Harvard University Press, 2007, 874 pp.

\title{
Charles Taylor: A Secular age
}

\section{Alexandre Bacelar Marques}

A Secular Age é um livro de peso. Literalmente, com suas quase 900 páginas e metaforicamente, pois Taylor se propõe a retomar o tema da secularização, adotandoo como o ponto de partida para uma interpretação dos destinos do Ocidente (ou, pelo menos, do Ocidente restrito ao que autor chama de Atlântico Norte) nos últimos quinhentos anos. O simples projeto da obra, sua ambição, independente de ter atingido ou não seus objetivos, é digno de nota.

É importante notar que o grande mérito do livro não está na originalidade do tema, mas no tratamento extremamente orgânico dos assuntos. O leitor vê assim uma imensa variedade de preocupações intelectuais aparecerem diante de seus olhos como se estivessem sempre e naturalmente em situação de contigüidade. $\bigcirc$ especialista fica contemplado com um grande painel interpretativo que relaciona cada problematização específica com o que podemos chamar, sem aspas, de grandes problemas do nosso tempo.

A expressão aqui, "problemas de nosso tempo", no caso de Charles Taylor, é um lugar comum ao qual devemos estar atentos. Em um estudo que é um enxerto de outro maior, sobre $\mathrm{Hegel}^{1}$, Taylor observa como podemos ler o projeto intelectual do grande filósofo do século XIX como uma tentativa, típica da consciência moderna, de abordar os problemas de seu próprio tempo. De certa forma, podemos dizer que ele continua, com esse livro, a tradição de Hegel sobre o que significa ser filósofo: alguém que interpreta o próprio período histórico desde um ponto de vista privilegiado, privilégio este que consiste em fazer com que os dilemas morais apareçam organicamente, como componentes de um mesmo todo. Ora, se seria estranho que tal fosse dito de pensadores de outros contextos, como a Antiguidade ou a Idade Média, é justamente à consciência do próprio período histórico, típica da modernidade, que Taylor faz jus.

Taylor então, grande crítico da modernidade e filósofo essencialmente anti-iluminista, toma para si uma tarefa caracteristicamente iluminista que é a de esclarecer o leitor sobre o mundo histórico que o circunda. Esta postura 
intelectual resume o tom crítico geral usado no livro: uma crítica dos valores modernos que - sem perder a contundência - consegue sempre abordá-los pelo que têm de melhor, de mais razoável e, não menos importante, de mais inevitável, de mais fatal (ou providencial). Não seria, talvez, correto dizer que se trata de um livro otimista; não se trata, isto é certo, de um livro reacionário. Mas talvez isso ainda não seja o mais importante; o mais importante é o fato de que Taylor nunca assume uma postura meramente contestatória. A crítica pós-moderna (mas não apenas ela), por exemplo, muitas vezes esgota-se na expressão de uma revolta. Este, definitivamente, não é o caminho adotado pelo autor de A secular Age.

Taylor vai além da mera contestação porque, ao mesmo tempo em que aponta para os problemas do que chama de ética da autenticidade, ou expressivismo (a principal característica da moral moderna, e tema de seu outro grande trabalho, As Fontes do Self ${ }^{2}$ ), ele está sempre disposto a: 1) considerar que é uma postura ética que possui apelo real a pessoas inteligentes e razoáveis e 2) considerar que é uma configuração moral que já faz parte, de fato, de um mundo, em que poucos de nós estaríamos dispostos a abdicar completamente de nossas conquistas. Taylor é, portanto, um crítico de sua própria época, mas um crítico que nunca considera a possibilidade de não estar inserido nela. Como ele mesmo diz, no início de As Fontes do self, trata-se de "apreender a combinação ímpar de grandeza e perigo, de grandeur et misere, que caracteriza a idade moderna" (1994:8).

Neste sentido, A Secular Age pode ser lido como uma apologia da experiência religiosa católica, e, se há algum vilão nessa grande narrativa (seria exagero dizer que há), esse papel cabe à Reforma Protestante e às mudanças que advieram a partir de suas concepções morais e teológicas. Taylor, entretanto, está muito longe de ser um católico destes que desejam que retornemos à Idade Média; ele está, pelo contrário, pronto a nos mostrar que não existe Era de Ouro do Cristianismo. Está claro para ele que para quem tem os olhos postos na eternidade, toda época é época de viver uma vida voltada para o transcendente, sendo que o que muda é apenas a natureza dos desafios. O fecho do livro é justamente um capítulo, intitulado Conversions, que discute o que significa crer em Deus no mundo de hoje. Deste capítulo, bastante criticado, vou dizer somente que Taylor nos apresenta uma visão extremamente rica do assunto - e isenta de qualquer tipo de apologia barata. Longe de ser uma visão de Deus politicamente conservadora, depois de passarmos pelas mais de 700 paginas anteriores, verificamos que os problemas abordados, assim como a terminologia, ambos provenientes da esquecida disciplina da teologia, não soam nem um pouco estranhos. Ao contrário, este é um dos muitos pequenos méritos do trabalho: contribuir para uma tendência, cada vez mais consolidada, de trazer a teologia novamente para o horizonte das ciências do homem. Fica claro, durante a leitura de A Secular Age, como a sociologia, a filosofia política a antropologia, a crítica literária, etc. só tem a ganhar com o estudo da tradição teológica e com o enfrentamento de seus problemas. 
Também nesse ponto Taylor mantém-se numa espécie de justo meio. Ele não pertence nem ao grupo de autores, como John Milbank, que tendem a considerar que todos os conceitos e problematizações das ciências humanas são uma espécie de teologia feita por outros meios, e nem ao grupo oposto, (tão vasto que é desnecessário exemplificar), que entende que a teologia simplesmente não interessa a quem "não acredita na Bíblia" a não ser, claro, como objeto de estudo. A chave para o argumento do livro está na própria maneira do autor delimitar seu objeto de estudo, isto é, no conceito de secularização que ele adota.

Existe uma virtude específica a qual possibilita que nosso autor possa construir um vasto painel explicativo que vai surgindo a partir de sua forma narrativa. Expliquemos esta virtude dizendo que ele adota o que pode ser chamado de "ponto de vista do espírito". Por que é isto que o livro é. Uma definição - uma das muitas boas definições possíveis - do escopo do trabalho seria dizer que o que foi levado a cabo foi uma história espiritual do Ocidente, de 1500 para cá. A literatura, a moda, a política, a moralidade, a economia, a história, aparecem tão bem articuladas justamente pelo fato de que o trabalho possui uma estrutura. É a esta estrutura que estou nomeando aqui de "ponto de vista do espírito" (expressão de que Taylor não se vale). Poderíamos dar outro nome, mais próximo da terminologia utilizada pelo autor: sentido de plenitude. Uma citação vai nos fazer compreender melhor:

Todos enxergamos nossas vidas e/ou o espaço dentro do qual nós vivemos nossas vidas como tendo certa forma morallespiritual. Em algum lugar, em alguma atividade ou condição, encontramos uma plenitude, uma riqueza; isto é, neste lugar (ou atividade ou condição) a vida é mais completa mais rica, mais profunda, mais digna de ser vivida, mais admirável, mais como ela deveria ser. Tal lugar pode ser um lugar de poder: freqüentemente o vivenciamos como comovente e inspirador. Pode ser que essa plenitude seja algo do qual podemos ter apenas, de longe, um vislumbre. Temos uma poderosa intuição sobre o que a plenitude deveria ser caso estivéssemos naquela condição de, por exemplo, paz - ou completude; ou caso pudéssemos agir naquele nível de integridade ou generosidade ou abandono ou auto-esquecimento. Algumas vezes, entretanto, momentos haverão de plenitude realmente vivida, de alegria e preenchimento, quando sentimos que nós mesmos estamos lá (:5, tradução livre).

É a partir, portanto, desta experiência de plenitude que Taylor vai estruturar sua narrativa. A história desde o ponto de vista do espírito é feita olhando de que maneira os diversos contextos sociais e intelectuais, os diversos projetos humanos que surgiram em nossa civilização estão ligados ao que entendemos ser 
uma vida plena, uma vida completa. $\mathrm{O}$ modo segundo o qual vivenciamos esse apelo é o que vai, portanto, servir de guia para o estudioso. Se dizemos que ele está na igualdade de todos os homens, se na soma das utilidades, se na verdade da ciência, na liberdade, ou se simplesmente negamos sua existência, é isso que vai determinar a forma espiritual do fenômeno humano.

A análise de Taylor é de natureza genealógica. Ocorre, porém, que, enquanto o chamado método genealógico, proveniente da matriz nietzschiana, celebrizado, como se sabe, com as obras de Michel Foucault, assume uma atitude de desmascaramento, procurando sempre achar o que há de prosaico, de banal, de sem sentido, por trás das configurações morais e epistemológicas, Taylor faz exatamente o oposto. $O$ método genealógico, nas mãos de Foucault, é uma recusa da idéia de origem (do "mito das origens", como ele mesmo diz), da idéia de início, de continuidade etc. dos fenômenos sócio-históricos; nas mãos de Taylor, é uma pesquisa sobre nossa relação com a realidade que nos transcende enquanto sujeitos. $\bigcirc$ homem é, por natureza, um ser incompleto. A Secular Age é, nesse sentido, uma história de como a cristandade latina vivenciou essa incompletude a partir das mudanças introduzidas com a Reforma.

Enquanto método de pesquisa histórica, a genealogia é sempre uma crítica à noção de autonomia do sujeito. Só que, enquanto a genealogia neo-nietzschiana é um desmascaramento, uma genealogia que podemos dizer "por baixo" ou "descendente", a de Taylor é uma genealogia "pelo alto", ou "ascendente" que procura sempre investigar, por trás dos diferentes compromissos humanos, seja com a moral, seja com a ciência, seja com a arte, diferentes modos de vivenciar nosso sentido de incompletude, isto é, de vivenciar o mistério da realidade que nos transcende.

Queira ou não, o homem (mesmo o ocidental) encontra-se solicitado por algo que está além de seu aqui e agora, pela possibilidade de uma transformação radical em sua realidade. Negar tal solicitação é apenas um dos muitos modos de vivenciá-la: "Parece-me que nossa situação (a perene situação humana?) é estar aberto a duas solicitações. Uma (em nossa civilização, pelo menos) é o apelo de uma perspectiva transformadora. A outra advém de um heterogêneo conjunto de resistências a este tipo de solicitação" (:435, tradução livre). Taylor parte, portanto, de uma ontologia. Se a genealogia neo-nietzschiana busca, em último caso, mostrar que "nada é tão admirável assim", a genealogia de Taylor nos diz que tudo é digno de admiração, porque tudo são maneiras de vivenciarmos nossa relação com o transcendente.

E este é o ponto de vista a partir do qual ele aborda as vicissitudes porque passou e vem passando o cristianismo no Ocidente.

Em nossa vida religiosa respondemos a uma realidade transcendente. Temos todos algum grau de percepção disto, o qual emerge do 
identificarmos e reconhecermos alguma modalidade daquilo que chamei plenitude, e buscarmos nos ligar a ela. Os modos de plenitude reconhecidos pelos humanismos exclusivos, e outros que ainda permanecem no interior da moldura imanente, estão assim respondendo a uma realidade transcendente mas sem o reconhecer (:768, tradução livre).

Todo o trabalho é informado por uma perspectiva de uma realidade transcendente. É nessa perspectiva que reside o especial interesse da abordagem proposta por Taylor para o problema da secularização. Essa abordagem consiste no seguinte: existem, de acordo com Taylor, três significados principais da palavra secularização. O primeiro é o significado que está associado a autores como Hobbes ou Maquiavel. Ele refere-se à possibilidade, hoje óbvia, que surgiu no Ocidente de que pudéssemos falar de política sem falar de Deus e pudéssemos, portanto, enxergar a religião de cada um como assunto privado; também associada a esta primeira dimensão da palavra secularização está a ideia de uma sociedade que não é governada por nenhuma "doutrina abrangente", isto é, nenhuma explicação última do cosmos que sirva como fonte do certo e do errado. Em suma, o Estado laico. O segundo sentido da secularização é a retirada da idéia de Deus ou, em sentido lato, de religião, não da vida política, mas da esfera privada dos indivíduos. Na região geográfica que Taylor localiza como Atlântico Norte, cada vez mais e mais pessoas, num processo que tem início no Renascimento (com um breve antecedente no mundo antigo, o epicurismo, mas sem maior significação social), passam a viver suas vidas sem sentir necessidade de falar em algum sentido último para elas, sem falar em Deus. Assim como era impossível, antes do período moderno, pensar em política sem pensar em Deus, era impossível pensar na vida moral dos indivíduos sem pensar na ordem superior na qual ela estava inserida; claramente não é o que ocorre hoje, quando um número cada vez maior de pessoas sente-se em paz com a ideia de que o universo como um todo não faz nem precisa fazer nenhum sentido. Se a palavra que resume o primeiro significado da secularização é laicismo, a que resume esse segundo significado é ateísmo.

Agora bem, saltando a questão de que, embora intuitiva, a relação entre estes dois significados é deveras complicada de se estabelecer, eles são rejeitados por Taylor pelo seguinte motivo: tanto o primeiro significado como, mais intensamente, o segundo significado refere-se a crenças, a práticas, a instituições. Já o foco de Taylor é: o que faz a vida mais humana melhor, mais louvável, mais digna de ser vivida? Como podemos alcançar este estado de plenitude? Antes do advento da modernidade, dificilmente poderia ser achada uma resposta para esta questão que não remetesse à religião e a Deus. Hoje, podemos pensar em respostas tais como a arte, a beleza, o amor ao próximo, o bem da comunidade, 
o bem do ser humano em geral ou a simples busca de prazer. É a esta metástase do horizonte de sentido que Taylor tem em mira com o termo secularização.

A pergunta, portanto, não é: como e por que passamos a considerar que o mundo da política possui uma lógica própria, distinta dos valores religiosos? Nem: por que deixamos, nós ocidentais, de crer em Deus? Mas: por que este anelo humano universal de plenitude, de contato com uma realidade mais real que nós mesmos, anelo este que antes era vazado em linguagem religiosa, passou a ser expresso em diversas outras linguagens? Formulando de outro modo: como Deus passou, ao longo dos últimos séculos, de única opção a não mais que uma opção entre muitas outras?

O termo secularização não se refere ao fato de a política ter-se tornado secular, ou a fato dos indivíduos terem deixado de freqüentar a igreja, mas ao fato de que a crença em Deus ocorre agora em condições bastante diferenciadas. A crença em Deus não acabou (não no sentido que os significados 1 e 2, listados acima, levam a crer). $O$ que mudou foi seu ambiente. Antes, a crença era ingênua. Era possível crer no Deus de Abraão como criador, como fonte do significado do cosmo (e de nossa vida moral), sem imaginar que esta ideia de completude, de plenitude, poderia ser vivenciada de muitas outras maneiras. Hoje, a vida espiritual se desenrola em um ambiente distinto. Nenhuma via escolhida tem o direito de entender-se como a única. Estamos o tempo inteiro sendo confrontados com formas distintas de vidas espirituais, com distintas fontes de plenitude. $O$ que antes só era encontrado em Deus e estava sob autoridade de seus representantes, o clero, hoje é encontrado na natureza, na arte ou na revolução.

Esta é a perspectiva a partir da qual Taylor vai estudar o problema, e é ela que torna possível, analiticamente, a abrangência de seu trabalho. $O$ defeito das outras duas perspectivas apontadas acima, a pespectiva da secularização como laicismo ou como ateísmo, é que ambas propõem implicitamente uma narrativa específica sobre a história ocidental. É da necessidade de evitar esta narrativa que advêm a necessidade de buscar também um novo ângulo para o problema. Que narrativa é esta que precisa ser evitada?

É a que nos conta a história espiritual do ocidente como uma "história de subtração”. Este molde narrativo está tão arraigado em nossa cultura que tendemos a vê-lo como única versão legítima dos fatos. Quando encaramos o problema da secularização a partir dos dois significados expostos acima, tendemos a ser conduzidos, quase imperceptivelmente, pela seguinte versão dos fatos: em nossa civilização (entenda-se: no Atlântico Norte) a religião foi saindo de cena gradativamente, à medida que ia sendo expulsa pelas luzes da ciência. Se as pessoas deixaram de acreditar na divindade dos reis, ou na influência dos espíritos foi porque Maquiavel lhes ensinou que os governantes são tão humanos como qualquer um de nós ou porque a psicologia lhes mostrou que as possessões 
demoníacas não passam de neuroses. Se a arqueologia demonstra que, antes dos homens, vieram os dinossauros, e Darwin descobre que as espécies não foram sempre da forma como as vemos hoje, então, Adão nunca existiu, a Bíblia está errada, e, logo, a tradição judaico-cristã é uma farsa. À medida que as pessoas foram sendo informadas, foram abandonado sua vida religiosa.

Embora esteja apresentado em forma de caricatura, este argumento está implícito quando vemos o problema da secularização apenas do ponto de vista das crenças e das práticas. O que está em jogo, para Taylor, no entanto, é algo mais profundo: são os motivos pelos quais entendemos que as pessoas e a sociedade aderem a projetos morais ou epistemológicos. Quando entendemos o processo de secularização como o longo processo em que as verdades da religião foram sendo refutadas pelas verdades da ciência, estamos implicitamente teorizando sobre as fontes da espiritualidade/moralidade dos homens. Estamos dizendo que nosso sentido de ordem resume-se a uma procura por "respostas objetivas" para "problemas objetivos". Queremos saber sobre história natural; a Bíblia não fala em dinossauros, logo, o livro do Gênese não tem significado para nós. Aliás, melhor ainda: seu significado é meramente poético, subjetivo, "literário"; ele diz respeito apenas à nossa sensibilidade, ao nosso "eu"; sua verdade é privada, e é a esta esfera que ela deve recolher-se. Posto que a razão apresenta respostas mais razoáveis, não apenas sobre a natureza, mas também sobre a moralidade (pense-se nas doutrinas morais racionalistas, como as de Kant), a religião vai declinando cada vez mais. Esta é a narrativa implícita nos significados 1 e 2 do problema da secularização, e o motivo pelo qual são rejeitados.

Ao leitor de A Secular Age, é oferecida uma perspectiva diferente: o homem ocidental deixou de ver-se como membro de uma ordem que possui um significado transcendente - um "cosmo" - e passou a enxergar o mundo exterior como não mais que um "universo", isto é, um conjunto natural fechado, composto de leis imutáveis e impessoais. Tudo bem. O problema é que esta passagem da visão da religião para a ciência não é uma simples passagem de uma teoria errada para uma teoria mais provável. O estabelecimento da visão copernicana do universo é uma mudança também de imaginário social (conceito riquíssimo em Taylor, objeto de uma obra anterior, Modern social imaginaries ${ }^{3}$, e do capítulo 4 desta resenhada).

Os espaços infinitos, tanto os espaços astronômicos quantos os espaços microscópicos, descobertos pela ciência, e dos quais o homem moderno acostumou-se a ver-se como parte, possuem um profundo impacto moral; eles fazem parte da própria maneira de visualizarmos nosso lugar no cosmo. Não é possível entender a história do Ocidente se começarmos pela negação desta realidade. Nem todas as descobertas da ciência possuem impacto moral, nem as que o possuem, como a teoria heliocêntrica, ou a teoria da evolução, são apenas isto, ou menos científicas por conta disso. É inegável, no entanto, que 
esse significado moral está diretamente ligado ao sucesso da instituição da ciência em nossa sociedade. Existe algo mais na lenta substituição da autoridade da religião pela autoridade da ciência que um refinamento teórico. Assim como podemos falar em conversões para as religiões, também podemos falar em conversões para a autoridade dos métodos científicos de conhecimento. Os capítulos 9, 10 e 11 são dedicados a isso. Taylor diz: "não posso aceitar a grande narrativa Whiggish de que elas (isto é, as conversões para a ciência) são determinadas por razões claras. Elas parecem caras dentro de um certo modelo, de fato, mas tal modelo nos atrai por um magote de razões, inclusive razões éticas" (:387, tradução livre). Em outras palavras, e remetendo ao que foi dito acima, a ciência é apenas um dos caminhos possíveis para a satisfação de nosso sentido de plenitude.

Isso não é para dizer que no livro constam discussões mais finas sobre o tópico da filosofia da ciência propriamente dito. Taylor apenas se interessa pelo significado moral que esta instituição assumiu em nossa sociedade. A ciência é apenas um de seus muitos assuntos e o estilo de lidar com os temas é sempre extensivo e nunca intensivo. O mérito da obra, como dissemos, está na articulação e na estrutura mais que nos detalhes. Isso não significa, absolutamente, dizer que o tratamento é superficial. É difícil evitar a sensação, entretanto, que alguns tópicos mereciam mais páginas que outros. Por isso também não se pode pensar que A Secular Age possua, propriamente, uma conclusão. O que Taylor faz nas páginas finais é rearticular os problemas, no que ele mesmo chama de dilemas, ou encruzilhadas, de acordo com a perspectiva adotada, a qual espero ter explicitado aqui. $O$ resultado é enriquecedor. É uma visão geral sobre os problemas mais atuais das ciências humanas.

Finalizo com a seguinte observação: o objetivo desta resenha, além de falar do escopo do livro, foi evidenciar o seu mérito. Procurei mostrar, até onde foi possível, qual foi a perspectiva de análise que permitiu a Taylor escrever uma obra tão rica; e entre falar do ângulo geral adotado pelo autor, ou dos temas específicos de que ele trata, foi dada prioridade à primeira opção.

Ocorre que esta escolha talvez passe uma ideia equivocada de que as discussões do livro são mais abstratas do que elas realmente são. Um das qualidades de Taylor enquanto filósofo, contudo, é justamente o constante diálogo que ele mantém com virtualmente todo o espectro das ciências humanas, da história, à psicologia. Ao lado das análises mais abstratas, estão as análises, digamos, mais históricas (ou sociológicas); dignas de nota, neste ponto, são as observações que ele tem a fazer sobre a sociedade disciplinar no século XVI assim como sobre o papel da religião na sociabilidade do século XIX. A acusação contrária talvez fosse mais justa: a de que Taylor se demora pouco em tópicos demasiadamente instigantes. A dimensão ética da ciência, mencionada acima, é apenas um tema, dentre muitos. Toda a parte teológica e de teoria literária também pode 
constar aqui como merecedora de estudos mais alongados. Que fique sendo esta, portanto, a crítica ao livro. Não apenas alguns pontos sobre teologia e filosofia moral poderiam ser melhor desenvolvidos, como a ausência de alguns autores soa quase estranha. É evidente que a percepção de qualquer ausência, numa obra de tal envergadura, é sempre uma questão pessoal, no entanto, cabe assinalar que a menção de autores como Kierkergaard, ou um diálogo mais extenso com as interpretações da modernidade de gente como Eric Voegelin (de quem Taylor, muitas vezes se aproxima, e que não é nunca citado), Hans Blummenberg (citado apenas de passagem), ou Carl Schmitt, só teria a enriquecer o leitor.

\section{Notas}

1 TAYLOR, Charles. (2005), Hegel e a sociedade moderna. São Paulo: Edições Loyola.

2 TAYLOR, Charles. (1994), As Fontes do Self - A Construção da Identidade Moderna. São Paulo: Edições Loyola.

3 TAYLOR, Charles. (2004). Modern Social Imaginaries. Durham: Duke University Press.

\footnotetext{
Alexandre Bacelar Marques (alexandrebmarques@yahoo.com.br) Mestrando em Ciência Política pelo Instituto Universitário de Pesquisas do Rio de Janeiro.
} 